Pacific Journal of Mathematics

ON A STRONGER VERSION OF WALLIS' FORMULA 


\title{
ON A STRONGER VERSION OF WALLIS' FORMULA
}

\section{R. RAO UPPULURI}

\begin{abstract}
In Mathematical Statistics, estimation of parameters which index the probability density functions of random variables is an interesting area. The object of estimation is to look for estimators which have 'desirable' properties. It turns out that the lower bounds on the variances of estimators can be used to derive some inequalities. This is illustrated here in connection with Wallis' formula.
\end{abstract}

We shall now cite some references where this idea is used. In the classic book on mathematical probability, Uspensky [10] remarks as follows: "There are many cases in which, by means of considerations belonging to the theory of probability, several identities or inequalities can be established whose direct proof sometimes involves considerable difficulty." He has exemplified this remark very beautifully in several contexts in the book. In 1955, Chassan [1] has given some inequalities involving trigonometric functions, obtained by comparing the variance of a minimum variance estimator with the variance of a less efficient estimator. In 1956, Gurland [4] has given an inequality satisfied by the Gamma function, which was also obtained by comparing the variances of two estimators by using the so-called Cramér-Rao lower bound for the variance of unbiased estimators. In 1959, Olkin [8] has given an extension of Gurland's inequality, by using the multivariate form of the probability density function used by Gurland [4]. In 1962, Gokhale [3] has given a different inequality for the Gamma function than that given by Gurland [4], by using an analogue of the CramérRao lower bound derived by Rao [9].

In 1962, Mann [7] has given a beautiful application of Statistical Inference. By constructing the most powerful regions of a given size, he has illustrated how one can deduce the arithmetic-geometric mean inequality, Hölder inequality, and other well-known inequalities. In a humorous vein he remarks at the end: "Thus we have derived Hölder's inequality from the fact that we cannot increase our knowledge on the milk yield of cows by flipping a coin or by measuring the weight of herrings."

In 1956, Gurland [5] has also given another illustration of the use of Cramér-Rao lower bound for the variance of unbiased estimators, which yielded a closer approximation to $\pi$, than the so-called Wallis' result. In this paper we shall pursue this idea and give stronger versions of Wallis' Formula, by using the so-called Bhattacharya bounds for the variance of estimators which is an extension of the Cramér-Rao bound. 
1. For $m=1,2,3, \cdots$

$$
\begin{aligned}
\sqrt{(m)} & <\frac{\Gamma(m+1)}{\Gamma\left(m+\frac{1}{2}\right)} \\
= & \frac{2 \times 4 \times 6 \times \cdots \times(2 m)}{1 \times 3 \times 5 \times \cdots \times(2 m-1) \times \Gamma\left(\frac{1}{2}\right)}<\sqrt{\left(m+\frac{1}{2}\right)}
\end{aligned}
$$

is one form of the celebrated formula of John Wallis.

In 1956, by an ingenious application of a basic theorem in Mathematical Statistics concerning unbiased estimators and a lower bound to their variances, Gurland [5] has given the following sharper inequalities:

$$
\sqrt{\left(m+\frac{1}{4}\right)}<\frac{\Gamma(m+1)}{\Gamma\left(m+\frac{1}{2}\right)}<\frac{\left(m+\frac{1}{2}\right)}{\sqrt{\left(m+\frac{3}{4}\right)}}
$$

$$
\text { for } m=1,2,3, \cdots \text {. }
$$

Pursuing this idea, we shall show how this result can be strengthened, and indicate how one can obtain much sharper bounds if one desires. We shall prove that:

$$
\begin{aligned}
\left\{m+\frac{1}{4}+\frac{9}{(48 m+32)}\right\}^{1 / 2} & <\frac{\Gamma(m+1)}{\Gamma\left(m+\frac{1}{2}\right)} \\
& <\left\{\frac{\left(m+\frac{1}{2}\right)^{2}}{m+\frac{3}{4}+\frac{9}{(48 m+56)}}\right\}^{1 / 2} .
\end{aligned}
$$

2. Before proceeding to prove (3), we shall state the theorem concerning Bhattacharya's bounds for the variance of unbiased estimators.

Let $X_{1}, X_{2}, \cdots, X_{n}$ by $n$ independent, identically distributed random variables, with probability density function $p_{\theta}(x)$, where the unknown parameter $\theta$ is a number in some open interval $D$ of the real line. Suppose $T\left(X_{1}, X_{2}, \cdots, X_{n}\right)$ is an unbiased estimate of $\theta$, i.e. $E(T)=\theta$, where, as usual, $E(T)$ denotes the mathematical expectation of the random variable $T\left(X_{1}, X_{2}, \cdots, X_{n}\right)$.

We shall assume the following regularity conditions:

(i ) $\partial \log p_{\theta}(x) / \partial \theta$ exists, for all $x$, and for all $\theta \in D$

(ii) $\int_{-\infty}^{\infty} \cdots \int_{-\infty}^{\infty} p_{\theta}\left(x_{1}\right) p_{\theta}\left(x_{2}\right) \cdots p_{\theta}\left(x_{n}\right) d x_{1} d x_{2} \cdots d x_{n}$ 
can be differentiated with respect to $\theta$, under the integral sign

(iii) $\int_{-\infty}^{\infty} \cdots \int_{-\infty}^{\infty} T\left(x_{1}, x_{2}, \cdots, x_{n}\right) p_{\theta}\left(x_{1}\right) \cdots p_{\theta}\left(x_{n}\right) d x_{1} \cdots d x_{n}$

can be differentiated with respect to $\theta$, under the integral sign

(iv) The matrix

$$
\left[\begin{array}{cccc}
\lambda_{11} & \lambda_{12} & \cdots & \lambda_{1 k} \\
\lambda_{21} & \lambda_{22} & \cdots & \lambda_{2 k} \\
\vdots & & \\
\lambda_{k 1} & \lambda_{k 2} & \cdots & \lambda_{k k}
\end{array}\right]
$$

is nonsingular, where

$$
\lambda_{i j}=E\left(S_{i} S_{j}\right)
$$

and

$$
S_{i}=\frac{1}{p_{\theta}\left(x_{1}\right) \cdots p_{\theta}\left(x_{n}\right)} \cdot \frac{\partial^{i}\left[p_{\theta}\left(x_{1}\right) \cdots p_{\theta}\left(x_{n}\right)\right]}{\partial \theta^{i}} .
$$

Then we have the:

THEOREM. The variance of $T\left(x_{1}, x_{2}, \cdots x_{n}\right)$, denoted by $\sigma_{T}^{2}$ satisfies $\sigma_{T}^{2} \geqq L_{k} \geqq L_{k-1} \geqq L_{k-2} \geqq \cdots \geqq L_{2} \geqq L_{1}$ where

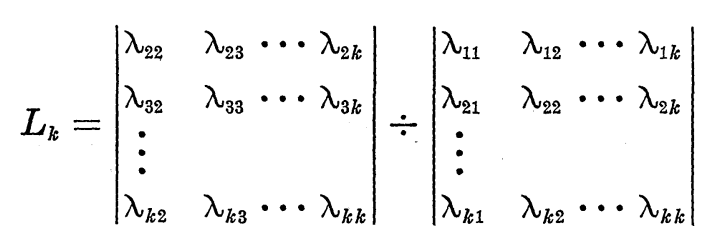

(and bars denote the corresponding determinants).

And we will have equality in $\sigma_{T}^{2} \geqq L_{k}$, if and only if $T$ is a linear function of $S_{1}, S_{2}, \cdots, S_{n}$.

For proof, see $\$ 2.3$, Lehmann [6]. We note that when $k=1$, we have the so-called Cramér-Rao inequality.

3. Proof of (3). Let $X_{1}, X_{2}, \cdots, X_{n}$ be a random sample from a normal population with mean 0 and variance $\sigma^{2}$, i.e.,

$$
p_{\sigma}(x)=\frac{1}{\sigma \sqrt{2 \pi}} \exp \left(\frac{-x^{2}}{2 \sigma^{2}}\right) \text {. }
$$

Then, it is well known that (see page 485, Cramer [2])

$$
T\left(X_{1}, X_{2}, \cdots, X_{n}\right)=\frac{\Gamma\left(\frac{n}{2}\right)}{\Gamma\left(\frac{n+1}{2}\right)}\left\{\frac{\sum_{i=1}^{n} X_{i}^{2}}{2}\right\}^{1 / 2}
$$


is an unbiased estimate of $\sigma$, and

$$
\sigma_{T}^{2}=\left\{\frac{n}{2} \frac{\Gamma^{2}\left(\frac{n}{2}\right)}{\Gamma^{2}\left(\frac{n+1}{2}\right)}-1\right\} \sigma^{2} .
$$

In this case, it turns out that:

$$
\begin{aligned}
& S_{1}=\frac{1}{\sigma}(Y-n), \quad \text { where } \quad Y=\left\{\frac{\sum_{i=1}^{n} X_{i}^{2}}{\sigma^{2}}\right\} \\
& S_{2}=\frac{1}{\sigma^{2}}\left\{(Y-n)^{2}-(Y-n)\right\}
\end{aligned}
$$

and

$$
\begin{aligned}
& \lambda_{11}=\frac{2 n}{\sigma^{2}}, \lambda_{12}=\lambda_{21}=\frac{6 n}{\sigma^{3}} \\
& \lambda_{22}=\frac{1}{\sigma^{4}}\left(12 n^{2}+34 n\right) .
\end{aligned}
$$

Therefore, for the case $k=2$, we have $\sigma_{T}^{2}>L_{2}$ (the equality was excluded because $T$ is not a linear function of $S_{1}$ and $S_{2}$ ), which implies:

$$
\left\{\frac{n}{2} \frac{\Gamma^{2}\left(\frac{n}{2}\right)}{\Gamma^{2}\left(\frac{n+1}{2}\right)}-1\right\} \sigma^{2}>\frac{\sigma^{2}}{2 n} \frac{6 n+17}{6 n+8},
$$

for $n=1,2, \cdots$.

For $n=2 m$, (4) may be written as:

$$
\frac{\Gamma^{2}(m+1)}{\Gamma^{2}\left(m+\frac{1}{2}\right)}>\frac{48 m^{2}+44 m+17}{48 m+32}=m+\frac{1}{4}+\frac{9}{48 m+32}
$$

$$
\text { for } m=1,2, \cdots
$$

and for $n=2 m+1$, (4) may be written as:

$$
\frac{\Gamma^{2}(m+1)}{\Gamma^{2}\left(m+\frac{1}{2}\right)}<\frac{(2 m+1)^{2}(12 m+14)}{48 m^{2}+92 m+51}=\frac{\left(m+\frac{1}{2}\right)^{2}}{m+\frac{3}{4}+\frac{9}{(48 m+56)}} \begin{array}{r}
m=1,2, \cdots .
\end{array}
$$

Thus (5) and (6) taken together prove (4). 


\section{REFERENCES}

1. J. B. Chassan, A statistical derivation of a pair of trigonometric inequalities, Amer. Math. Monthly 62 (1955), 353-356.

2. H. Cramér, Mathematical Methods of Statistics, Princeton University Press, 1946.

3. D. V. Gokhale, On an inequality for gamma functions, Skandinavisk Aktuarietidskrift (1962), 213-215.

4. J. Gurland, An inequality satisfied by the gamma function, Skandinavisk Aktuarietidskrift (1956), 171-172.

5. — On Wallis' formula, Amer. Math. Monthly 63, (1956), 643-645.

6. E. L. Lehmann, Notes on the Theory of Estimation, University of California Press, 1950.

7. H. B. Mann, An inequality suggested by the theory of statistical inference, Illinois J. Math. 6 (1962), 131-136.

8. I. Olkin, An inequality satisfied by the gamma function, Skandinavisk Aktuarietidskrift, (1959), 37-39.

9. B. R. Rao, On an analogue of Cramer-Rao inequality, Skandinavisk Aktuarietidskrift (1959), 213-215.

10. J. V. Uspensky, Introduction to Mathematical Prohability, McGraw-Hill, 1937. (See page 37 for the quote.)

Received October 6, 1965. Presented at the Symposium on Inequalities held at Wright-Patterson AFB during 19-27 August 1965. Research sponsored by the U.S. Atomic Energy Commission under contract with the Union Carbide Corporation.

Mathematics Division

OAK Ridge National Laboratory

OAK RIDGE, TENNESSEE 



\section{PACIFIC JOURNAL OF MATHEMATICS}

\section{EDITORS}

\author{
H. SAMELSON \\ Stanford University \\ Stanford, California \\ J. P. JANS \\ University of Washington \\ Seattle, Washington 98105
}

\author{
J. DUGUNDJI \\ University of Southern California \\ Los Angeles, California 90007 \\ RICHARD ARENS \\ University of California \\ Los Angeles, California 90024
}

\section{ASSOCIATE EDITORS}
E. F. BECKENBACH
B. H. NeumanN
F. WOLF
K. YOSIDA

\section{SUPPORTING INSTITUTIONS}

\author{
UNIVERSITY OF BRITISH COLUMBIA \\ CALIFORNIA INSTITUTE OF TECHNOLOGY \\ UNIVERSITY OF CALIFORNIA \\ MONTANA STATE UNIVERSITY \\ UNIVERSITY OF NEVADA \\ NEW MEXICO STATE UNIVERSITY \\ OREGON STATE UNIVERSITY \\ UNIVERSITY OF OREGON \\ OSAKA UNIVERSITY \\ UNIVERSITY OF SOUTHERN CALIFORNIA
}

STANFORD UNIVERSITY

UNIVERSITY OF TOKYO

UNIVERSITY OF UTAH

WASHINGTON STATE UNIVERSITY

UNIVERSITY OF WASHINGTON

AMERICAN MATHEMATICAL SOCIETY CHEVRON RESEARCH CORPORATION TRW SYSTEMS

NAVAL ORDNANCE TEST STATION 


\section{Pacific Journal of Mathematics}

\section{Vol. 19, No. 1 \\ May, 1966}

A. R. Brodsky, The existence of wave operators for nonlinear equations... 1

Gulbank D. Chakerian, Sets of constant width................... 13

Robert Ray Colby, On indecomposable modules over rings with minimum condition....................................... 23

James Robert Dorroh, Contraction semi-groups in a function space ....... 35

Victor A. Dulock and Harold V. McIntosh, On the degeneracy of the Kepler



James Arthur Dyer, The inversion of a class of linear operators ......... 57

N. S. Gopalakrishnan and Ramaiyengar Sridharan, Homological dimension of Ore-extensions ................................. 67

Daniel E. Gorenstein, On a theorem of Philip Hall ................. 77

Stanley P. Gudder, Uniqueness and existence properties of bounded observables..................................... 81

Ronald Joseph Miech, An asymptotic property of the Euler function ....... 95

Peter Alexander Rejto, On the essential spectrum of the hydrogen energy and related operators ............................... 109

Duane Sather, Maximum and monotonicity properties of initial boundary



Peggy Strait, Sample function regularity for Gaussian processes with the parameter in a Hilbert space ........................... 159

Donald Reginald Traylor, Metrizability in normal Moore spaces ........... 175

Uppuluri V. Ramamohana Rao, On a stronger version of Wallis' formula ...............................

Adil Mohamed Yaqub, Some classes of ring-logics....... 